\title{
Mechanisms of oxidative stress and vascular dysfunction
}

\author{
Z S Nedelikovic, N Gokce, J Loscalzo
}

Postgrad Med J 2003;79:195-200

The endothelium regulates vascular homoeostasis through local elaboration of mediators that modulate vascular tone, platelet adhesion, inflammation, fibrinolysis, and vascular growth. Impaired vascular function contributes to the pathogenesis of atherosclerosis and acute coronary syndromes. There is growing pathophysiological evidence that increased generation of reactive oxygen species and oxidative stress participates in proatherogenic mechanisms of vascular dysfunction and atherothrombosis. In this review, the role of oxidative stress in mechanisms of vascular dysfunction is discussed, and potential antioxidant strategies are reviewed.

See end of article for authors' affiliations

Correspondence to: Dr Joseph Loscalzo, Whitaker Cardiovascular Institute, 80 East Concord Street W 507, Boston, MA USA; jloscalz@bu.edu

Submitted 11 September 2002

Accepted

29 January 2003
T he endothelium plays a critical part in the regulation of vascular function through elaboration of paracrine factors that maintain vascular tone, inhibit platelet and inflammatory cell adhesion, promote fibrinolysis, and limit vascular proliferation. ${ }^{1}$ Endothelial dysfunction refers to a pathophysiological disease state in which homoeostatic functions of endothelial cells are perturbed promoting vasospasm, thrombosis, intimal growth, inflammation, and plaque rupture leading to tissue ischaemia, atherothrombosis, and infarction. ${ }^{2}$ Impaired endothelial function is associated with atherothrombotic risk factors and atherothrombotic disease, is pathophysiologically linked to acute cardiovascular syndromes, and provides prognostic information with regard to increased cardiovascular risk. ${ }^{3}$

A central feature of impaired endothelial function in the presence of cardiac risk factors and under pathological conditions is impairment in endothelium-derived nitric oxide (EDNO) bioactivity. ${ }^{5}$ Nitric oxide is produced in endothelial cells from the conversion of L-arginine to L-citrulline through the tightly regulated activity of (endothelial) nitric oxide synthase. EDNO regulates vascular tone through a dilator action on vascular smooth muscle cells that depends on soluble guanylyl cyclase activation and consequent increase in intracellular cyclic $3^{\prime} 5^{\prime}$ guanosine monophosphate. ${ }^{\prime}$ Additional antiatherogenic functions of EDNO relate to inhibition of platelet activity, leucocyte adhesion, and vascular smooth muscle cell proliferation. Reduced nitric oxide synthesis or inactivation appears to be a common functional disturbance in the presence of cardiac risk factors and atherothrombosis. Other abnormalities in endothelial function relate, in part, to increased expression of adhesion molecules supporting inflammatory cell recruitment to the vessel wall; enhanced release of con- strictor agents such as angiotensin-II that promote vascular growth and alter vascular tone; and loss of antithrombotic function through reduced production of prostacyclin and fibrinolytic factors.

Mechanisms underlying impaired endothelial function in various disease states such as hypertension, diabetes mellitus, hypercholesterolaemia, and atherosclerosis are likely multifactorial. There is growing evidence that oxidative stress (defined as an imbalance between endogenous oxidants and antioxidants in favour of the former) contributes to mechanisms of vascular dysfunction. $^{7}$ These observations fit well with the recognition that increased oxidative stress may be central to the atherogenic process. ${ }^{8}$ In this review, we will discuss the role of oxidative stress in endothelial dysfunction and its contribution to vascular disease, and discuss potential therapeutic antioxidant strategies.

VASCULAR OXIDANT STRESS, IMPAIRED EDNO BIOACTION, AND LOW DENSITY LIPOPROTEIN OXIDATION

Mammalian cells produce energy by reducing molecular oxygen to water during aerobic respiration. During this process, intermediates referred to as reactive oxygen species are generated that include superoxide anion, hydroxyl radicals, and hydrogen peroxide (fig 1). Under homoeostatic conditions, these molecules likely play a regulatory part in cellular function, and antioxidant defences modulate their steady state balance. Owing to their highly biologically reactive properties, reactive oxygen species have the potential to interact with proteins, lipids, and DNA, and their excessive production has been implicated in the pathogenesis of various disease states including aging, reperfusion injury, dementia, and atherosclerosis. $^{7}$

A dominant mechanism of impaired vascular nitric oxide bioavailability relates to its oxidative inactivation by superoxide. Superoxide anion rapidly reacts with nitric oxide and eliminates its biological activity. ${ }^{9}$ There is considerable evidence that vascular production of superoxide is increased in hypercholesterolaemia, diabetes mellitus, hypertension, and cigarette use. ${ }^{10}{ }^{11}$ Arterial tissue isolated from rabbits fed a hypercholesterolaemic diet releases increased amounts of superoxide anion that is associated with impaired

Abbreviations: $A C E$, angiotensin converting enzyme; EDNO, endothelium-derived nitric oxide; eNOS, endothelial nitric oxide synthase; HOPE (study), Heart Outcomes Prevention Evaluation (study); LDL, low density lipoprotein; MAPK, mitogen activated protein kinase; $\mathrm{NADH} / \mathrm{NAD}(\mathrm{P}) \mathrm{H}$, nicotinamide dinucleotide (phosphate); $N F-\kappa B$, nuclear factor kappa $B$; ox-LDL, oxidised low density lipoprotein; SOD, superoxide dismutase 
Superoxide dismutase

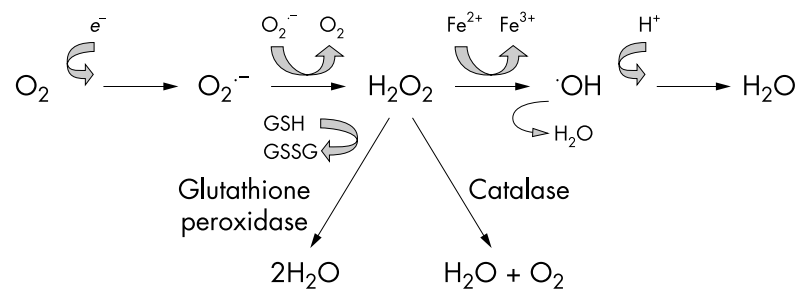

Figure 1 Generation of reactive oxygen species. Molecular oxygen $\left(\mathrm{O}_{2}\right)$ reacts with an impaired electron $\left(e^{-}\right)$to form the superoxide anion $\left(\mathrm{O}_{2}\right)$. Superoxide is converted to hydrogen peroxide $\left(\mathrm{H}_{2} \mathrm{O}_{2}\right)$ by the enzyme superoxide dismutase. Hydrogen peroxide undergoes spontaneous conversion to the highly reactive hydroxyl radical $(\mathrm{OH})$. Alternatively, it can be detoxified via either glutathione peroxidase or catalase to water $\left(\mathrm{H}_{2} \mathrm{O}\right)$ and oxygen (GSH, reduced glutathione; GSSG, oxidised glutathione).

EDNO dependent dilation..$^{10}$ In patients, the finding that an infusion of recombinant human superoxide dismutase (SOD) improves acetylcholine-mediated coronary dilation further supports the importance of increased superoxide anion production as a mechanism of endothelial dysfunction. ${ }^{12}$ Inhibiting endogenous copper-zinc SOD in normal vascular tissue decreases nitric oxide action. ${ }^{13}$

In addition to abrogating the antiatherogenic effects of nitric oxide, the combination of superoxide anion with nitric oxide generates peroxynitrite, a highly reactive intermediate that fuels lipid peroxidation, generation of reactive aldehydes and nitrogen oxides, and protein nitration supporting proatherogenic modification of low density lipoprotein (LDL). The "oxidative modification hypothesis of atherosclerosis" refers to the central role of oxidised LDL (ox-LDL) in the atherosclerotic process and provides the basis for a mechanistic link between hypercholesterolaemia and vascular disease. ${ }^{14}$ This hypothesis proposes that LDL initially localises in the vascular subendothelial space and is subsequently oxidatively modified by resident vascular cells. Although mechanisms of LDL oxidation in vivo are incompletely understood, endothelial cells, vascular smooth muscle cells, and monocytes are collectively able to oxidise LDL. Macrophages within the vessel wall internalise ox-LDL via scavenger receptors, and develop into lipid-rich "foam cells". In contrast to regulated uptake of native (unoxidised) LDL by apo $\mathrm{B} / \mathrm{E}$ receptors, the incorporation of ox-LDL into foam cells through scavenger receptor pathways is not subject to negative feedback regulation. Thus, progressive lipid accumulation within lipid laden macrophages occurs in an unchecked manner, and is believed to represent a dominant mechanism of subintimal fatty streak evolution that characterises the earliest manifestations of atherosclerosis. ${ }^{15}$ Evidence that LDL oxidation occurs in vivo is supported by studies demonstrating that antibodies against ox-LDL react with atherosclerotic lesions but not normal arteries, and their titres correlate with extent of atherosclerosis. ${ }^{14}$

In addition to fuelling lipid accumulation in foam cells, ox-LDL contributes to vascular dysfunction and atherosclerotic plaque formation by additional mechanisms. Ox-LDL stimulates expression of proinflammatory signals including monocyte chemotactic protein-1 and intercellular adhesion molecule- 1 that facilitate monocyte recruitment and adhesion to the vessel wall. ${ }^{16}$ Further, ox-LDL directly inactivates nitric oxide, is cytotoxic to endothelial cells, ${ }^{17}$ stimulates vascular smooth muscle cell proliferation, and upregulates tissue factor and plasminogen activator inhibitor-1 expression that have the potential to support atherothrombosis. ${ }^{18}$

In addition to LDL oxidation, reaction of reactive oxygen species with cell membrane bound fatty acids can promote a vicious cycle of continued oxidative damage, resulting in
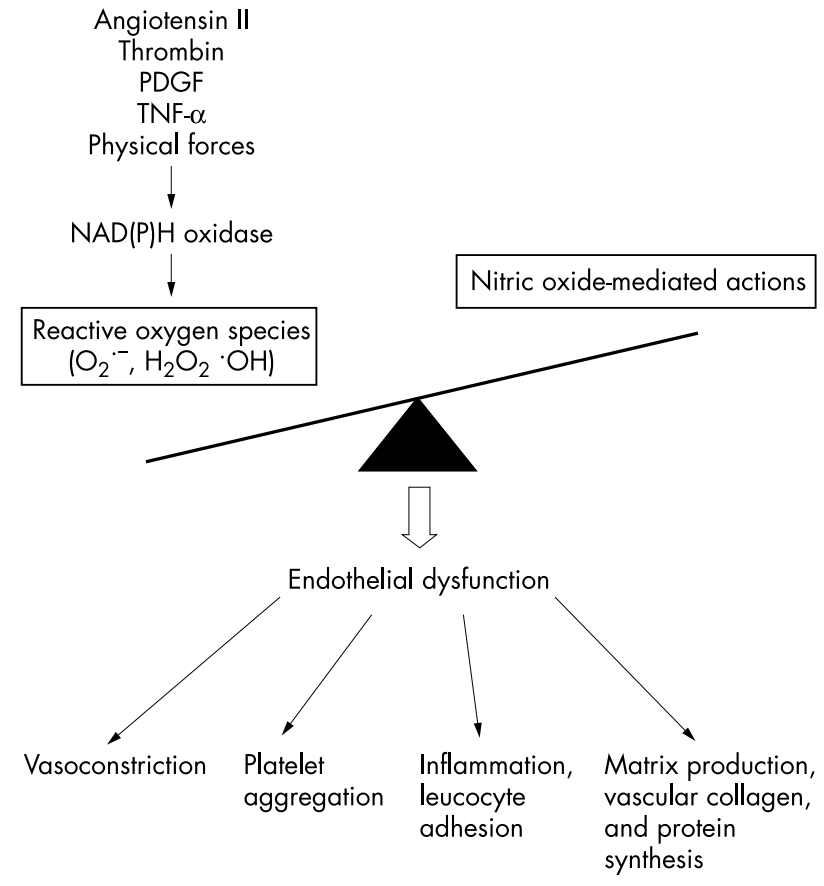

Figure 2 Balance of oxidative stress and nitric oxide action on vascular function $\left(\mathrm{H}_{2} \mathrm{O}_{2}\right.$, hydrogen peroxide; $\mathrm{NAD}(\mathrm{P}) \mathrm{H}$, nicotinamide dinucleotide (phosphate); PDGF, platelet derived growth factor; $\mathrm{O}_{2}$, superoxide anion; $\mathrm{OH}$, hydroxyl radical; TNF- $\alpha$, tumour necrosis factor- $\alpha$ ).

alterations in cell membrane permeability and functional impairment in cellular transport and signalling. For example, superoxide anion may combine with transition metal ions to form hydroxyl radical and hydrogen peroxide, which are also relevant to the molecular underpinnings of cellular dysfunction. ${ }^{19}$

\section{SOURCES OF REACTIVE OXYGEN SPECIES}

A variety of enzymatic and non-enzymatic sources of reactive oxygen species exist in blood vessels. ${ }^{20}$ The primary biochemical source of reactive oxygen species in the vasculature, particularly of superoxide, appears to be the membraneassociated nicotinamide dinucleotide (phosphate) (NADH/ $\mathrm{NAD}(\mathrm{P}) \mathrm{H})$ oxidase enzyme complex. ${ }^{21}$ This system catalyses the reduction of molecular oxygen using $\mathrm{NAD}(\mathrm{P}) \mathrm{H}$ as an electron donor, generating superoxide. The function of this enzyme complex is most easily understood in the context of the activated neutrophil, wherein it generates large amounts of toxic superoxide anion and other reactive oxygen derivatives important in bactericidal function. NADH/NAD $(\mathrm{P}) \mathrm{H}$ oxidases are also functional in membranes of vascular endothelial and smooth muscle cells, and fibroblasts providing a constitutive source of superoxide anion. Various cytokines and hormones relevant to the pathogenesis of vascular disease and reduced nitric oxide bioavailability (fig 2 ) including angiotensin II, thrombin, tumour necrosis factor- $\alpha$, and platelet derived growth factor upregulate vascular NADH/NAD(P)H oxidase activity and superoxide production. ${ }^{21}$

$\mathrm{NADH} / \mathrm{NAD}(\mathrm{P}) \mathrm{H}$ oxidase activity plays an important part in angiotensin II-mediated hypertension. Administration of angiotensin II to rats raises blood pressure and increases vascular superoxide production, and this effect is dependent on activation of membrane-associated oxidases. ${ }^{11}$ Impaired arterial relaxation to acetylcholine and increased production of superoxide anion are also features of angiotensin II-induced, but not catecholamine-induced, hypertension. ${ }^{22}$ The increase in superoxide production and impairment in vessel relaxation during angiotensin II infusion is prevented by concurrent 
administration of losartan, suggesting that activation of this oxidase system occurs by an angiotensin II receptor dependent mechanism. Increased NADH/NAD(P)H oxidase activity may also be important in other cardiovascular diseases. Superoxide is increased in aortic tissue of cholesterol fed rabbits and in blood vessels of patients with coronary artery disease, hypercholesterolaemia, and diabetes mellitus. ${ }^{23}$ There is increased expression of angiotensin converting enzyme (ACE) in atherosclerotic plaques that serve as a source of local angiotensin II production. Shoulder regions of coronary lesions are characterised by more abundant NADH/NAD(P)H oxidase dependent superoxide activity that may be relevant to plaque inflammation and propensity for rupture. ${ }^{24}$ The link between angiotensin II, ACE activity, and superoxide anion production underscores the general importance of the renin-angiotensin system in cardiovascular disease.

Another source of vascular superoxide is the xanthine oxidoreductase enzyme system that catalyses the oxidation of hypoxanthine to xanthine during purine metabolism. ${ }^{20}$ Early stages of atherosclerosis are associated with increased superoxide anion production by endothelial cells, and inhibition of xanthine oxidase activity with oxypurinol improves impaired vasodilation in hypercholesterolaemic patients. ${ }^{25} \mathrm{~A}$ third potential source of vascular reactive oxygen species production is endothelial nitric oxide synthase (eNOS). eNOS is a cytochrome P450 reductase-like enzyme that requires cofactors including tetrahydrobiopterin, flavin nucleotides, and $\mathrm{NAD}(\mathrm{P}) \mathrm{H}$ for transfer of electrons to a guanidino nitrogen of L-arginine to form nitric oxide. L-arginine and tetrahydrobiopterin deficiency are associated with uncoupling of the L-arginine-nitric oxide pathway resulting in decreased formation of nitric oxide, and increased eNOS-mediated generation of superoxide (and peroxynitrite). Tetrahydrobiopterin repletion improves endothelial function in chronic smokers, ${ }^{26}$ and augments nitric oxide bioactivity in hypercholesterolaemic humans.$^{27}$ Additional intracellular sources of reactive oxygen species include mitochondrial respiration, cyclo-oxygenases, lipoxygenases, and cytochrome P450 mono-oxygenase, but the relative contribution and clinical relevance of these enzymatic sources remain incompletely understood.

The biological activity of reactive oxygen species depends upon their relative balance in relation to intracellular antioxidant defences. For example, SOD catalyses the metabolism of superoxide to hydrogen peroxide. Hydrogen peroxide may combine with transition metal ions to generate hydroxyl radical intermediates, or be detoxified to water by glutathione peroxidase or catalase (fig 1). Other intracellular antioxidants such as ascorbic acid, $\alpha$-tocopherol, and glucose-6-phosphate dehydrogenase also play an important part in the regulation of intracellular redox status. Ascorbic acid supplementation improves EDNO-dependent dilation in patients with coronary artery disease and diabetes mellitus. ${ }^{28}{ }^{29} \mathrm{~A}$ balance of nitric oxide-mediated versus oxidant-mediated signals may determine the ambient phenotypic behaviour of endothelial cells. In disease states, increased production or activity of reactive oxygen species overwhelms endogenous antioxidant protection, tipping the scale towards atherothrombogenesis (fig 2).

\section{ROLE OF REACTIVE OXYGEN SPECIES IN CELL SIGNALLING, GENE EXPRESSION, AND VASCULAR GROWTH}

There is growing evidence to suggest that reactive oxygen species, particularly superoxide and hydrogen peroxide, participate in vascular cell signalling and proatherogenic gene expression by modulation of redox-sensitive transcription and transduction pathways. ${ }^{30}$ In the setting of increased oxidative stress, endothelial cells lose their protective phenotype, and express proinflammatory molecules. These molecules include vascular cell adhesion molecule-1, intercellular adhesion molecule-1, and monocyte chemotactic protein-1, all of which facilitate endothelial-leucocyte interactions and initiate early stages of atherosclerosis. Expression of inflammatory signals is, in part, controlled by a redox-sensitive transcriptional regulatory protein nuclear factor kappa $\mathrm{B}(\mathrm{NF}-\kappa \mathrm{B}) .{ }^{31} \mathrm{NF}-\kappa \mathrm{B}$ is also important in proliferative signals involved in vascular smooth muscle cell growth, vascular remodelling, and atherogenesis. Cultured cells overexpressing catalase exhibit suppressed activation of NF- $\mathrm{KB}$ in response to tumour necrosis factor- $\alpha,{ }^{30}$ while those overexpressing SOD exhibit intracellular accumulation of hydrogen peroxide and NF- $\mathrm{\kappa B}$ activation. Further evidence for the involvement of reactive oxygen species in NF- $\mathrm{\kappa B}$ activity is provided by studies demonstrating its inhibition by antioxidants such as $\mathrm{N}$-acetylcysteine and pyrrolidine dithiocarbamate.

Oxidant species also play a regulatory part in other aspects of intracellular signalling. Mitogen activated protein kinase (MAPK) and tyrosine kinases consist of key regulatory proteins that control cellular response to growth and stress signals. ${ }^{190}$ In vascular cells, growth factors and angiotensin II are powerful activators of extracellular signal-regulated kinase and p38 MAPK that stimulate smooth muscle cell proliferation and fibroblast migration through mechanisms that involve hydrogen peroxide These proliferative responses drive neointimal growth and likely play a part in atheroma development and restenosis. Stimulation of vascular smooth muscle cells by the mitogen platelet derived growth factor increases intracellular production of hydrogen peroxide and tyrosine phosphorylation. ${ }^{32}$ This process is abrogated by enhancing intracellular concentrations of free radical-scavenging enzymes such as catalase, and by the antioxidant $\mathrm{N}$-acetylcysteine. Reactive oxygen species modulate both Akt kinase and caspase activity, which play a part in endothelial cell proliferation and activation of apoptotic signals leading to endothelial cell loss, respectively. ${ }^{33}$

Reactive oxygen species also modulate collagen matrix metabolism through activation of proteolytic matrix metalloproteinases that play an important part in plaque behaviour and stability. ${ }^{34}$ Matrix metalloproteinase expression is increased in shoulder regions of atherosclerotic plaques where its increased activity may increase the propensity for plaque rupture. ${ }^{35}$ Atherectomy specimens from patients with unstable coronary syndromes exhibit increased expression of reactive oxygen species compared with individuals with stable angina, supporting a mechanistic role of reactive oxygen species in plaque composition and behaviour..$^{36} \mathrm{~N}$-acetylcysteine prevents matrix metalloproteinases-9 expression and activation in hypercholesterolaemic rabbits, implicating a potential role for antioxidant treatment in modulating plaque stability. ${ }^{37}$

\section{TREATMENT STRATEGIES}

\section{Antioxidant vitamins}

The central role of oxidant stress in the pathogenesis of vascular dysfunction has generated considerable interest in antioxidant therapy for cardiovascular disease. As previously discussed, several antioxidants such as ascorbic acid (vitamin C), $\alpha$-tocopherol (vitamin E), glutathione, tetrahydrobiopterin, and $\mathrm{N}$-acetylcysteine have been shown to improve endothelial function and nitric oxide bioaction in cultured cells, and in animal and human clinical studies of vascular reactivity. In addition, epidemiological studies suggest that individuals with higher antioxidant intake have reduced cardiovascular risk. ${ }^{38}$ To date, vitamin $\mathrm{E}$ has been the predominant antioxidant tested in large clinical trials. Despite an initial small study demonstrating a therapeutic benefit of vitamin $\mathrm{E}$ on reducing non-fatal myocardial infarctions, ${ }^{39}$ more recent randomised, placebo controlled, large scale trials of vitamin $\mathrm{E}$ intake have been disappointing. In the GISSI-Prevenzione study that involved 11324 patients, vitamin E supplementation (300 mg/day) to patients after 
myocardial infarction had no significant effect on cardiovascular endpoints. ${ }^{40}$ In the Heart Outcomes Prevention Evaluation (HOPE) substudy, treatment with 400 IU/day of vitamin E failed to demonstrate a beneficial effect on cardiovascular outcomes after 4.5 years of therapy. ${ }^{41}$ In a three year double blind study, antioxidant treatment with a combined daily regimen of vitamin E (800 IU), vitamin C (1000 mg), $\beta$-carotene $(25 \mathrm{mg})$, and selenium $(100 \mu \mathrm{g})$ had no effect on angiographic coronary lesions or cardiovascular events. ${ }^{42}$ In the very recently completed Medical Research Council/British Heart Foundation Heart Protection Study of 20536 high risk individuals with atherosclerotic disease or diabetes, treatment with vitamin $E$, vitamin $C$, and $\beta$-carotene for five years had no effect on mortality rate compared with placebo. ${ }^{43}$

On first look, it appears difficult to reconcile these negative studies in view of the large body of evidence supporting the role of oxidative stress in cardiovascular disease. On closer examination, several limitations of these trials may be brought to light before refuting a role for antioxidant treatment. Previous studies were conducted almost entirely on patients with existing coronary disease, and the role of antioxidant therapy for primary prevention remains an open question. In addition, there is considerable debate as to whether certain antioxidants, particularly vitamin E, have any significant in vivo activity to attenuate meaningfully all aspects of reactive oxygen species-mediated atherogenic mechanisms. ${ }^{44}$ For example, although vitamin E can inhibit LDL oxidation in vitro, it is unlikely to achieve sufficiently high concentrations in the vascular microenvironment to interfere effectively with all components of oxidative stress, and has limited activity against superoxide and peroxynitrite driven processes. ${ }^{45}$ Another limitation of the published clinical trials is the lack of biological markers that would identify individuals most likely to benefit from treatment, analogous to the relationship between plasma cholesterol and lipid lowering therapy. A recent study demonstrated that the ability of vitamin $\mathrm{C}$ to improve vascular dilation identifies patients at risk for cardiovascular events, and such investigations may represent initial steps towards defining a population that may benefit most from treatment. ${ }^{4}$ Lastly, there has been debate about duration of therapy, dosing regimens, and the potential role of antioxidant combinations on endpoints that are being addressed in ongoing clinical trials.

\section{ACE inhibitors}

ACE inhibitor therapy improves cardiovascular outcomes in patient with hypertension, congestive heart failure, and coronary artery disease. The recent HOPE trial demonstrated that ACE inhibitors produce a dramatic decrease in cardiovascular events independent of the effect on left ventricular function, and blood pressure lowering, supporting the idea that this intervention may have direct effects on vascular function. ${ }^{46}$ The most relevant evidence for such a mechanism was provided by the observation that quinapril treatment for six months improved coronary endothelial function in patients with coronary artery disease. ${ }^{47}$ Given the link between the renin-angiotensin system and vascular $\mathrm{NAD}(\mathrm{P}) \mathrm{H}$ oxidase activity, ACE inhibitors may act as "antioxidants" in part by limiting angiotensin II-mediated superoxide production by $\mathrm{NAD}(\mathrm{P}) \mathrm{H}$ oxidase at its source and, thus, preventing superoxide-mediated inactivation of EDNO. ACE inhibitors may also affect downstream effects of superoxide limiting hydrogen peroxide formation and vascular proliferation, consistent with observations that ramipril reduced progression of carotid intimal thickening. ${ }^{48}$ ACE inhibitor therapy may also limit peroxynitrite generation and lipid peroxidation, and downregulate activation of redox-sensitive proinflammatory signals.

\section{Key references}

- Gokce N, Keaney JF Jr, Vita JA. Endotheliopathies: clinical manifestations of endothelial dysfunction. In: Loscalzo J, Shafer Al, eds. Thrombosis and hemorrhage. 2nd Ed. Baltimore: Williams and Wilkins, 1998: 901-24.

- Keaney JF Jr, ed. Oxidative stress and vascular disease. Kluwer Academic Publishers, 2000.

- Griendling KK, Sorescu D, Ushio-Fukai M. NADP(H) oxidase. Role in cardiovascular biology and disease. Circ Res 2000;86:494-501.

- Yusuf S, Sleight P, Pogue J, et al. Effects of an angiotensinconverting-enzyme inhibitor, ramipril, on cardiovascular events in high-risk patients. The Heart Outcomes Prevention Evaluation Study Investigators [see comments] [published erratum appears in N Engl J Med 2000;342:748]. N Engl J Med 2000;342:145-53.

- Heart Protection Study Collaborative Group. MRC/BHF Heart Protection Study of cholesterol lowering with simvastatin in 20,536 high-risk individuals: a randomised placebo- controlled trial. Lancet 2002;360:7-22.

\section{Statins}

Hydroxymethylglutaryl coenzyme A reductase inhibitors, or statins, were developed as a means to lower LDL cholesterol. Recent evidence, however, suggests that they are potent agents for improving endothelial function, and limiting inflammatory responses, including those mediated by NF- $\mathrm{KB}$ activation. ${ }^{49}$ These several actions of statins independent of their cholesterol lowering effects likely account for the benefits of these agents in improving outcomes in patients with coronary heart disease who had normal or low levels of LDL cholesterol. ${ }^{50} 51$ Importantly, owing to their antiinflammatory effects, statins can be considered antioxidant, as well, since inflammatory responses, especially cytokinemediated leucocyte and endothelial cell activation, promote reactive oxygen species generation. Thus, statins should be added to the list of antioxidant therapies that are currently available for the treatment of patients with atherothrombosis or risk factors for atherothrombosis.

In conclusion, oxidant stress alters normal endothelial function, supporting proinflammatory, prothrombotic, proliferative, and vasoconstrictor mechanisms that support the atherogenic process. Impaired nitric oxide bioactivity and increased oxidative stress are common features of disease states associated with atherosclerosis. Antioxidant treatment in clinical trials to date, predominantly with vitamin E, failed to improve cardiovascular outcomes, and ongoing clinical studies are designed to address the effects of alternative antioxidant regimens.

\section{QUESTIONS (TRUE (T)/FALSE (F); ANSWERS AT END OF REFERENCES)}

Q1. The principal biochemical source of reactive oxygen species in the vasculature is:

(A) NADH/NAD $(\mathrm{P}) \mathrm{H}$ oxidase

(B) Xanthine oxidoreductase

(C) Superoxide dismutase

(D) Glucose-6-phospate dehydrogenase

Q2. Reactive oxygen species contribute to mechanisms of atherosclerotic plaque vulnerability through activation of:

(A) Nitric oxide

(B) Matrix metalloproteinases

(C) Tetrahydrobiopterin

(D) Catalase 
Q3. Which of the following may exert their beneficial effects through antioxidant mechanisms?

(A) Angiotensin converting enzyme inhibitors

(B) Hydroxymethylglutaryl coenzyme A reductase inhibitors

(C) Both (A) and (B)

(D) None of the above

Q4. The endothelial form of nitric oxide synthase (eNOS) can be a source of reactive oxygen species: true or false

Q5. Reactive oxygen species upregulate expression of inflammatory signals through nuclear factor kappa B: true or false Q6. Superoxide enhances endothelium-derived nitric oxide activity: true or false

\section{Authors' affiliations}

Z S Nedelikovic, N Gokce, J Loscalzo, Evans Department of Medicine and Whitaker Cardiovascular Institute, Boston University School of Medicine, Boston, Massachusetts

\section{REFERENCES}

1 Vane JR, Anggard EE, Botting RM. Regulatory functions of the vascular endothelium. N Engl J Med 1990;323:27-36.

2 Gokce N, Keaney JF Jr, Vita JA. Endotheliopathies: clinical manifestations of endothelial dysfunction. In: Loscalzo J, Shafer Al, eds. Thrombosis and hemorrhage. 2nd Ed. Baltimore: Williams and Wilkins, 1998: 901-24.

3 Schachinger V, Britten MB, Zeiher AM. Prognostic impact of coronary vasodilator dysfunction on adverse long-term outcome of coronary heart disease. Circulation 2000;101:1899-906.

4 Heitzer T, Schlinzig T, Krohn K, et al. Endothelial dysfunction, oxidative stress, and risk of cardiovascular events in patients with coronary artery disease. Circulation 2001;104:2673-8.

5 Vita JA, Treasure CB, Nabel EG, et al. Coronary vasomotor response to acetylcholine relates to risk factors for coronary artery disease. Circulation 1990:81:491-7.

6 Ludmer PL, Selwyn AP, Shook TL, et al. Paradoxical vasoconstriction induced by acetylcholine in atherosclerotic coronary arteries. N Engl J Med 1986;315:1046-51.

7 Keaney JF Jr, ed. Oxidative stress and vascular disease. New York: Kluwer Academic Publishers, 2000.

8 Koida G, Harrison DG. Interactions between NO and reactive oxygen species: pathophysiological importance in atherosclerosis, hypertension,

9 Gryglewski RJ, Palmer RM, Moncada S. Superoxide anion is involved in the breakdown of endothelium-derived vascular relaxing factor. Nature 1986;320:454-6.

10 Ohara Y, Peterson TE, Harrison DG. Hypercholesterolemia increases endothelial superoxide anion production. J Clin Invest 1993:91:2546-51.

11 Rajagopalan S, Kurz S, Munzel T, et al. Angiotensin II-mediated hypertension in the rat increases vascular superoxide production via membrane NADH/NADPH oxidase activation. Contribution to alterations in vasomotor tone. J Clin Invest 1996:97:1916-23.

12 Meredith IT, Anderson TJ, Yeung AC, et al. Superoxide dismutase restores endothelial vasodilator function in human coronary arteries in vivo. Circulation 1993;88:1-467 (abst).

13 Mugge A, Elwell JK, Peterson TE, et al. Release of intact endothelium-derived relaxing factor depends on endothelial superoxide dismutase activity. Am J Physiol 1991;260:C219-25.

14 Steinberg D, Parthasarathy S, Carew TE, et al. Beyond cholesterol. Modifications of low-density lipoprotein that increase its atherogenicity. N Engl J Med 1989;320:915-24.

15 Witztum JL, Steinberg D. Role of oxidized low density lipoprotein in atherogenesis. J Clin Invest 1991;88:1785-92.

16 Navab M, Imes SS, Hama SY, et al. Monocyte transmigration induced by modification of low density lipoprotein in cocultures of human aortic wall cells is due to induction of monocyte chemotactic protein 1 synthesis and is abolished by high density lipoprotein. J Clin Invest 1991;88:2039-46.

17 Chin JH, Azhar S, Hoffman BB. Inactivation of endothelium-derived relaxing factor by oxidized lipoproteins. J Clin Invest 1992;89:10-18.

18 Berliner JA, Heinecke JW. The role of oxidized lipoproteins in atherogenesis. Free Radic Biol Med 1996;20:707-27.

19 Wolin $M$. Interactions of oxidants with vascular signaling systems. Arterioscler Thromb Vasc Biol 2000;20: 1430-42.

20 Cai H, Harrison DG. Endothelial dysfunction in cardiovascular diseases. The role of oxidant stress. Circ Res 2000;87:840-4

21 Griendling KK, Sorescu D, Ushio-Fukai M. NADP(H) oxidase. Role in cardiovascular biology and disease. Circ Res 2000;86:494-501.

22 Laursen JB, Rajagopalan S, Galis Z, et al. Role of superoxide in angiotensin II-induced but not catecholamine-induced hypertension. Circulation 1997; 95:588-93.
23 Guzik T, West N, Black E, et al. Vascular superoxide production by $\mathrm{NAD}(\mathrm{P}) \mathrm{H}$ oxidase. Association with endothelial dysfunction and clinical risk factors. Circ Res 2000:86:e85-90.

24 Sorescu D, Weiss D, Lassegue B, et al. Superoxide production and expression of Nox family proteins in human atherosclerosis. Circulation 2002; 105: 1429-35.

25 Cardillo C, Kilcoyne CM, Cannon RO, et al. Xanthine oxidase inhibition with oxypurinol improves endothelial vasodilator function in hypercholesterolemic but not in hypertensive patients. Hypertension 1997:30:57-63.

26 Ueda S, Matsuoka H, Miyazaki H, et al. Tetrahydrobiopterin restores endothelial function in long-term smokers. J Am Coll Cardiol 2000;35:71-5

27 Stroes E, Kastelein J, Cosentino F, et al. Tetrahydrobiopterin restores endothelial function in hypercholesterolemia. J Clin Invest 1997:99:41-6.

28 Gokce N, Keaney JF Jr, Frei B, et al. Long-term ascorbic acid administration reverses endothelial vasomotor dysfunction in patients with coronary artery disease. Circulation 1999;99:3234-40.

29 Timimi FK, Ting HH, Haley EA, et al. Vitamin C improves endothelium-dependent vasodilation in patients with insulin-dependent diabetes mellitus. J Am Coll Cardiol 1998;31:552-7.

30 Kunsch C, Medford RM. Oxidative stress as a regulator of gene expression in the vasculature. Circ Res 1999:85:753-66.

31 Valen G, Yan Z, Hansson GK. Nuclear factor kappa-B and the heart. J Am Coll Cardiol 2001;38:307-14.

32 Sundaresan $M, Y u Z$, Ferrans V, et al. Requirement for generation of $\mathrm{H}_{2} \mathrm{O}_{2}$ for platelet-derived growth factor signal transduction. Science 1995;270:298-301

33 Irani K. Oxidant signaling in vascular cell growth, death, and survival. A review of the roles of reactive oxygen species in smooth muscle and endothelial cell mitogenic and apoptotic signaling. Circ Res 2000;87: 179-83.

34 Channon KM. Oxidative stress and coronary plaque stability. Arterioscler Thromb Vasc Biol 2002;22:1751-2.

35 Galis ZS, Sukhova GK, Lark MW, et al. Increased expression of matrix metalloproteinases and matrix degrading activity in vulnerable regions of human atherosclerotic plaques. J Clin Invest 1994;94:2493-503.

36 Azumi H, Inoue $\mathrm{N}$, Ohashi $\mathrm{Y}$, et al. Superoxide generation in directional coronary atherectomy specimens of patients with angina pectoris. Important role of NAD(P)H oxidase. Arterioscler Thromb Vasc Biol 2002;22: 1838-44

37 Galis ZS, Asanuma K, Godin D, et al. N-acetyl-cysteine decreases the matrix-degrading capacity of macrophage-derived foam cells: new target for antioxidant therapy? Circulation 1998;97:2445-53.

38 Diaz MN, Frei B, Vita JA, et al. Antioxidants and atherosclerotic heart disease. N Engl J Med 1997;337:408-17.

39 Stephens NG, Parsons A, Schofield PM, et al. Randomised controlled trial of vitamin $E$ in patients with coronary disease: Cambridge Heart Antioxidant Study (CHAOS). Lancet 1996;347:781-6.

40 Anonymous. Dietary supplementation with n-3 polyunsaturated fatty acids and vitamin $E$ after myocardial infarction: results of the GISSI-Prevenzione trial. Gruppo Italiano per lo Studio della Sopravvivenza nell'Infarto miocardico. Lancet 1999:354:447-55.

41 Yusuf S, Dagenais G, Pogue J, et al. Vitamin E supplementation and cardiovascular events in high-risk patients. N Engl J Med 2000;342:154-60

42 Brown BG, Zhao XQ, Chait $A$, et al. Simvastatin and niacin, antioxidant vitamins, or the combination for the prevention of coronary disease. $N$ Engl J Med 2001:345:1583-92.

43 Heart Protection Study Collaborative Group. MRC/BHF Heart Protection Study of antioxidant vitamin supplementation in 20,536 high-risk individuals: a randomised placebo- controlled trial. Lancet 2002;360:23-33

44 Steinberg D, Witztum J. Is the oxidative modification hypothesis relevant to human atheroslcerosis? Do the antioxidant trials conducted to date refute the hypothesis? Circulation 2002:105:2107-1 1 .

45 Munzel T, Keaney JF Jr. Are ACE inhibitors a "magic bullet" against oxidative stress? Circulation 2001:104:1571-4.

46 Yusuf S, Sleight P, Pogue J, et al. Effects of an angiotensin-converting-enzyme inhibitor, ramipril, on cardiovascula events in high-risk patients. The Heart Outcomes Prevention Evaluation Study Investigators [see comments] [published erratum appears in N Eng J Med 2000;342:748]. N Engl J Med 2000;342:145-53.

47 Mancini GB, Henry GC, Macaya C, et al. Angiotensin-converting enzyme inhibition with quinapril improves endothelial vasomotor dysfunction in patients with coronary artery disease. The TREND (Trial on Reversing ENdothelial Dysfunction) Study. Circulation 1996;94:258-65

48 Lonn E, Yusuf S, Dzavik V, et al. Effects of ramipril and vitamin $E$ on atherosclerosis. The Study to Evaluate Carotid Ultrasound Changes in Patients Treated with Ramipril and Vitamin E (SECURE). Circulation 2001:103:919-25

49 Takemoto $\mathbf{M}$, Liao JK. Pleiotropic effects of 3-hydroxy-3-methylglutaryl coenzyme A reductase inhibitors. Arterioscler Thromb Vasc Biol 2001;21:1712-19.

50 Long-ferm Intervention with Pravastatin in Ischemic Disease (LIPID) Study Group. Prevention of cardiovascular events and death with pravastatin in patients with coronary heart disease and a broad range of initial cholesterol levels. N Engl J Med 1998;339:1349-57.

51 Heart Protection Study Collaborative Group. MRC/BHF Heart Protection Study of cholesterol lowering with simvastatin in 20,536 high-risk individuals: a randomised placebo- controlled trial. Lancet 2002;360:7-22. 


\section{ANSWERS}

1. (A). The principal source of reactive oxygen species in the vasculature is $\mathrm{NADH} / \mathrm{NAD}(\mathrm{P}) \mathrm{H}$ oxidase. Other sources include xanthine oxidoreductase and endothelial nitric oxide synthase. Superoxide dismutase converts superoxide to hydrogen peroxide. Glucose-6-phospate dehydrogenase modulates intracellular antioxidant defenses.

2. (B). Reactive oxygen species enhance matrix metalloproteinase activity that degrades collagen and destabilises atherosclerotic plaques. Catalase detoxifies hydrogen peroxide. Tetrahydrobiopterin is a cofactor for nitric oxide synthase.
3. (C). Both angiotensin converting enzyme inhibitors and hydroxymethylglutaryl coenzyme A reductase inhibitors may exert their potential beneficial actions through antioxidant mechanisms, independent of their blood pressure and lipid lowering effects.

4. True. Uncoupling of the L-arginine-nitric oxide pathway, via a deficiency of critical enzymatic cofactors, may result in increased superoxide production.

5. True. Nuclear factor kappa B is a redox-sensitive transcriptional regulatory protein important in upregulation of proinflammatory cell surface molecules.

6. False. Superoxide inactivates nitric oxide.

\section{BENCH $>$ PRESS}

\section{New PMJ online submission and review system}

am pleased to inform authors and reviewers of Postgraduate Medical Journal's new online submission and review system. Bench $>$ Press is a fully integrated electronic system which uses the internet to allow rapid and efficient submission of manuscripts, and the entire peer review process to be conducted online. Authors can submit their manuscript in any standard word processing software. Graphic formats acceptable are: .jpeg, .tiff, .gif, and .eps. Text and graphic files are automatically converted to PDF for ease of distribution and reviewing purposes. Authors are asked to approve their submission before it formally enters the reviewing process.

To access the system click on "SUBMITTING YOUR MANUSCRIPT" on the PMJ homepage: http://www.postgradmedj.com/ or you can access Bench>Press directly at http://submitpmj.bmjjournals.com/.

We are very excited with this new development and we would encourage authors and reviewers to use the online system where possible. It really is simple to use and should be a big improvement on the current peer review process. Full instructions can be found on Bench>Press and PMJ online. Please contact Natalie Davies, Project Manager, ndavies@bmjgroup.com for further information.

\section{Pre-register with the system}

We would be grateful if all $P M J$ authors and reviewers pre-registered with the system. This will give you the opportunity to update your contact and expertise data, allowing us to provide you with a more efficient service.

\section{Instructions for registering}

l. Enter http://submit-pmj.bmjjournals.com.

2. Click on "Create a new account" in the upper left hand side of the Bench>Press homepage.

3. Enter your email address in the space provided.

4. Choose a password for yourself and enter it in the spaces provided.

5. Complete the question of your choice to be used in the event you cannot remember your password at a later time (this will be needed if you forget your password).

6. Click on the "Complete step l" button at the bottom of the screen.

7. Check the email account you registered under. An email will be sent to you with a verification number and URL.

8. Once you receive the email, copy the verification number and click on the URL

hyperlink. Enter the verification number in the relevant field. Click on "Verify me". This is for security reasons and to check that your account is not being used fraudulently.

9. Enter/amend your contact information, and update your expertise data. 